\title{
LOS DÍAS QUE ESTREMECIERON CHILE
}

\author{
The days that shook Chile
}

\section{RESUMEN}

Quisiera "comprender" lo que (nos) ha acontecido y no deja de acontecer. ¿Qué puede ser esta alteridad que desde el 18 de octubre de 2019 viene modificando o resignificando las (nuestras) vidas? El presente ejercicio examina los nuevos vínculos que desde el "estallido" se han establecido entre las representaciones, las subjetividades, los cuerpos, los tiempos.

Palabras claves: estallido; 18 de octubre 2019; representaciones.

\section{ABSTRACT}

I would like to "understand" what has happened to us and it's still happening. What could be this otherness that since October 18, 2019 has been modifying or resignifying our lives? This exercise examines the new links that have been established since the "uprising" between representations, subjectivities, bodies, times.

Keywords: uprising; October 18, 2019; representations.

\section{UNIVERSUM}

Revista de Humanidades y Ciencias Sociales

\section{CARLOS OSSANDÓN B.}

Doctor en Filosofía. Profesor Titular de la Universidad de Chile

Correo electrónico:

cob2002@u.uchile.cl

ORCID: 0000-0002-2854-8014

ResearchGate:

Scholar.google:

Academia.edu:

Artículo recibido el 3 de marzo, 2020. Aceptado el 25 de marzo, 2020.

DOI:

Web: http://universum.utalca.cl | ISSN: 0716-498X - 0718-2376 
Quisiera "comprender" lo que (nos) ha acontecido y no deja de acontecer. ¿Qué puede ser esta alteridad que desde el 18 de octubre de 2019 viene modificando o resignificando las (nuestras) vidas? Si el acto de "comprender" no es ajeno al gesto de empatizar, si es algo más que "explicar", pudiera no estar demás dejarnos llevar, "escuchar" (también "interpretar" o "forcejear" puntualizaría Deleuze), recordando esa vieja tradición que prestó sus oídos a unas voces que parecían provenir del más allá (Giannini, 1979: 9-12); voces y cuerpos que, en el caso que nos interesa, y sin revelación ni trascendencia mediante, vinieron de una muy amplia gama de "condenados en los subterráneos de la ciudad" que lograron un buen día irrumpir, salir a la superficie, ser vistos, como bien metaforiza Rodrigo Karmy ("A la superficie: 18 de octubre de 2019") lo acontecido el día del "estallido" en el Metro de Santiago.

En aquel 18 de octubre de 2019, y los días que le siguieron, se alteró o se desplazó muy drásticamente, y con una rapidez sorprendente, un tipo de relación social que hasta ese momento se presentaba casi como definitiva: una suerte de emanación que hacía creer que provenía de las cosas mismas. Lo que tuvimos fue — se podría decir — un "acontecimiento", una singularidad histórica, una "partición” — diría Rancière — que hizo visible lo que no existía para un orden autoconcebido como "oasis"; una experiencia — dicho desde otro ángulo- que transformó las subjetividades, redistribuyó las posiciones y las funciones, desjerarquizó y puso las cosas de una manera distinta a la habitual. Todo esto - claro está - expresando grados e intensidades distintas, según la escena o el día que se trate. Como toda "singularidad" histórica, no adscrita a ninguna predeterminada "filosofía de la historia", aunque no por ello un "milagro", representa un desafío abierto a las formas de abordarla o pensarla.

Un nuevo tipo de vínculo se creó entre las representaciones, las subjetividades, los cuerpos, los tiempos. Esta nueva conjunción, donde sus distintos componentes se determinan mutuamente, generó un efecto momentáneamente devastador e insoportable para los poderes. El colectivo, con toda su diversidad y transversalidad, se apropió de la calle y - lo que 
es más importante - de la dimensión simbólica-política-material desde la cual se instituye cualquier sociedad. El orden, amenazado en su médula, no soportando la plebeyización de las hablas, la caótica irrupción que emanaba de los subterráneos, intuitivamente o muy rápidamente entendió la urgencia de reducir la re-vuelta a una expresión manipulable recurriendo para ello a elementos inconscientes, terroríficos, profundamente arcaicos podríamos decir, ahora liberados de toda contención. El ancestral miedo al caos, a lo informe, a las larvas, a la anticultura (Eliade, 1981: 32) fue aquello que planeó en la gigantesca foto de la portada de El Mercurio el día siguiente de la destrucción de algunas estaciones del Metro de Santiago, exteriorizando así con toda su carga de miedo aquello que, aunque siempre inconscientemente presente, nunca se debiera exteriorizar sin más o sin precauciones.

Es precisamente el enlace y a la vez radical conflicto entre un "mundo" constituido y su contraparte y sostén, lo que se hizo particularmente patente: por un lado, un mundo que se desgarra y que busca atolondradamente- y sin respetar derechos fundamentales - mantenerse como tal y, por otro lado, otro cuya potencia o agón desfundamentador se sobrepone a su cotidiano y pesado disciplinamiento y resignación. Ambos violentos, por supuesto, aunque de muy distinto signo y por lo tanto no homologables. El marco fue la explosiva convivencia, en un enfrentamiento cara a cara, de dos mundos en uno, inconmensurables aunque abordables (Rancière, 2012: 60): ${ }^{1}$ allí la experiencia "política", la salida de los subterráneos, ya no reducida a la participación en encuestas o en disputas electorales, se desencadena dentro y en contra de los abusos neoliberales y de una "administración" que — desafiada — muestra su rostro más feroz.

De un día para otro, disruptivamente, en las paredes de las calles aparecieron palabras nuevas (evasión, despertar, dignidad), siglas $\mathrm{o}$ significados poco divulgados hasta ese momento (Yuta, ACAB, Primera línea), reconocimientos olvidados, memorias dislocadas que renegaban de su violencia de origen, del duro precio o dolor que en el cuerpo y en el alma estas

\footnotetext{
1 Ver también Córdova, 2018.
} 
retenciones han debido pagar (Nietzsche, 1991: 65-71).Como si ese día y los siguientes el repetitivo y alabado "emprendedor" hubiese perdido fuerza en beneficio de un más alegre o desenfadado protagonismo social; como si las frías leyes del mercado, el individuo aislado en su deuda, o la mujer abusada, se hubiese trastrocado en un "común" más amplio, cálido y atrevido que pudo desdoblarse: ser el que se es en la situación de dominio y simultáneamente otro en la rebeldía. Se abrió así —incluyendo unas violencias disfuncionales (saqueos) afines a un régimen de desigualdad y corrupción- una reconexión y comunicación de gran intensidad vital que dejó pendiente la construcción a nivel macro de sociabilidades o redes más transversales o consolidadas.

En estos redescubrimientos o reposiciones, y en distintas escenas de punzante contrafactualidad, jugaron su rol figuras nuevas, tal como el "Pareman", mezcla de encapuchado criollo y gladiador romano; la reposición de algunas menos nuevas, como el negro "Matapacos" o el bailarín callejero "Sensual Spiderman"; y la resignificación contestataria o simplemente festiva de figuras aparentemente anodinas tales como el empeñoso "Baila Pikachú" de Lo Hermida o el sureño "Nalcaman". Fueron todos ellos los nuevos "Avengers" o superhéroes chilenos; figuras que, más que conceptuales o simbólicas, prefería entenderlas como singulares energéticos más bien, y no como la reproducción de ciertos arquetipos individualizantes tradicionales. ${ }^{2}$ El curioso caso de Karol Dance se aleja de esta lista y podría tener que ver con el castigo, a través de la mofa o la simple chacota, a un machismo y a una farándula abusivamente presente en los canales de televisión.

El reconocimiento de otras matrices o posibilidades de vivir la vida, tuvo su correlato en determinadas áreas de la sensibilidad y de la vivencia. Los cuerpos bailaron y cantaron, y lo que se escuchó fue una extraña y creadora mezcla de tiempos, de tardías reparaciones, que se alimentaron de operaciones igualmente inéditas: el "pueblo unido" salió de las catacumbas, de su lugar arqueológico, y adquirió una dimensión más universal y de superación de la atomización neoliberal; el baile de los que "sobran" atravesó la dictadura y la

2 Esta última idea, la advertencia crítica sobre el rol de los arquetipos o "modelos ejemplares", me fue sugerida por la socióloga Rosario Fernández el 25 de diciembre de 2019. 
postdictadura y adquirió un rango de concepto socio-político que envidiaría Alan Badiou; y el "derecho de vivir en paz" se presentó como una especie de síntesis entre lo que ya no se quiere más y ese horizonte nuevo, sin balines que mutilan ojos, al que se aspira. Por otra parte, la ex Plaza Italia, bautizada o emergida como Dignidad, en su diferencia con otros espacios no "consagrados", saturada ahora de "ser" y "potencia", se vivió y tiende a vivirse más nítidamente con el correr del tiempo como aquel lugar que simboliza el recomienzo de todo (Eliade, 1981: 25 - 32).

En este nuevo entramado de representaciones, cuerpos y sensibilidades, el inédito despliegue y extensión de la bandera mapuche se presentó como el inicio de una nueva relación con lo cultural y políticamente escamoteado. Sin la presencia y conducción de los partidos políticos, ni de la clásica figura de la "clase obrera" organizada, se contó, en cambio, con lo que tenemos de más esencial o permanente, haciendo más ostensible que nunca lo históricamente no resuelto, la compleja dialéctica entre autonomía, reparación y participación. Y la confluencia de las banderas mapuche y chilena, simbolizando, dice Rodrigo Karmy, a la "indiada", al "sobrante", al "resto", y no necesariamente a los "trabajadores del mundo" que responde a otro modelo de sociedad, le dio paradójicamente cuerpo a lo que no tiene cuerpo político, a ese "lugar sin lugar en que acampa el sitio baldío, más allá de toda representación” ("Los indios de Chile", 20 diciembre 2019: 104).

Hasta la vivencia del tiempo cambió. Acelerado y comprimido a la vez, ya no dilatado o en "grado cero", el tiempo se puso del lado de la desujeción o del desprendimiento, desarmando en pocos días lo que parecían arraigados disciplinamientos y rutinas, haciendo patente y sensible la fragilidad o la finitud de todo. Este tiempo acelerado y comprimido, exhibiendo su propia maleabilidad, nos expuso a la incertidumbre, al desasosiego y al conflicto que acompaña la existencia, al vivir juntos y quizá al ser mismo. La politicidad de esta vivencia se hizo evidente. Nunca la relación entre ontología, subjetividad y política habían sido tan íntimas en estos últimos 30 años.

Sin prever las emergencias de subjetividades a tal punto diversas y desbordantes, de inéditas y múltiples potencias de "auto-posicionamiento", 
“desdoblamiento" y "transformación de sí", que cuestionarán tanto los "fundamentos" y "mandatos" establecidos ${ }^{3}$ como las figuras de la "población" reducida a números o la de la "gente" hasta ese entonces prevalecientes, la llamada "clase política" se vio obligada a firmar un acuerdo parlamentario, después refrendado institucionalmente, que responde ciertamente a un mundo y a una sensibilidad distinta de la descrita: su temple ya no es festivo, sus colores - cuando los hay - no son los de las calles, y trae - en su separación del movimiento social, de sus representaciones e intensidades- su propio y radical vicio de origen.

Sin negar - todo lo contrario - la necesidad de dar una proyección genuinamente democrática, institucional, ampliamente deliberativa, plural, sin trampas, al "estallido"; esta proyección — nunca definitiva — tendrá espesor y legitimidad si se conecta o se nutre de ese "élan" o re-vuelta profundamente política que ha estremecido Chile; si no se aparta o es parte constituyente más bien de esa apropiación (subrayemos la voz "apropiación”) o reconfiguración diversa de mundo que inauguró el 18 de octubre del año 2019. Objetivo nada fácil dada la dificultad de "institucionalizar" sin desfigurar los impulsos "antiautoritarios" — sensibles, corporales, múltiples — del "estallido" (o "rebelión", más bien), por un lado, así como la de evitar la reducción o disolución simple de lo "político" en lo "social", realidad esta última contradictoria y no nítidamente autonomizable, por otro lado.

Se podrían destacar otras dificultades. Advertir, por ejemplo como se ha hecho- que el cambio de la Constitución política no supone necesariamente una transformación del tipo de dominio, o que este cambio pudiese ahogar o consumar el impulso o el poder constituyente o creador del demos. Al lado de estas aprensiones, quedan también en la retina otras escenas: el modo, por ejemplo, como una pobladora de La Pintana combina en un solo haz la convicción política con su recuperada dignidad en la calle, adquiriendo esta combinación el peso de una "roca", expresión esta de "buen sentido" diríamos gramscianamente inspirados.

3 La política es, para Rancière, "una ruptura específica de la lógica del arkhé” (2006: 63). 


\section{BIBLIOGRAFÍA}

Arancibia, Juan Pablo. Tragedia y melancolía. Idea de lo trágico en la filosofía política contemporánea. Santiago de Chile: La Cebra, 2016.

Castillo, Alejandra. “¿Hacia un Estado global seguritario?”. Antigonafeminista, 25 noviembre 2019. Consultado el 7 enero 2020.

Córdova, Diego. Del escándalo al éxodo. Repensando la teoría democrática de Jacques Rancière. Tesis para optar al grado de Magíster en Comunicación Política, ICEI, Universidad de Chile, 2018.

Echeverría, Luciana; Rebolledo, Javier; Tótoro, Dauno. Hasta que valga la pena vivir. La revolución de octubre de 2019 en los muros de Santiago. Santiago: Ceibo, 2019.

Eliade, Mircea. Lo sagrado y lo profano. Barcelona: Guadarrama, 1981.

Giannini, Humberto. Esbozo para una historia de la filosofía. Santiago: Dionysos, 1979.

Karmy, Rodrigo.“A la superficie: 18 de octubre de 2019”. El desconcierto. 19 de octubre 2019. Consultado el 7 enero 2020.

"Los indios de Chile", Palabra Pública. Universidad de Chile, 20 diciembre 2019.Consultado el 7 enero 2020.

Nietzsche, Friedrich. La genealogía de la moral. Madrid, Alianza Editorial, 1991.

Rancière, Jacques (avec Adnen Jdey). La méthode de la scène. Fécamp: Lignes, 2018.

El desacuerdo. Política y filosofía. Buenos Aires: Nueva Visión, 2012. Política, policía, democracia. Santiago: Lom, 2006.

Stiegler, Bernard. De la misère symbolique. Paris: Galilée, 2002.

Tello, Andrés (ed.). Gobierno y Desacuerdo. Diálogos interrumpidos entre Foucault y Rancière. Viña del Mar: Communes, 2016. 